\title{
Design and Interaction in the Narratives of Decoration Discourse
}

\author{
Heba Zaytoon \\ Department of English Language and Literature, Faculty of Women, Ain Shams University, Egypt \\ E-mail: radwa.anan77@gmail.com
}

Received: 05-10-2016

Accepted: 17-12-2016

Published: 01-05-2017 doi:10.7575/aiac.ijalel.v.6n.3p.1

Advance Access Published: March 2017

URL: http://dx.doi.org/10.7575/aiac.ijalel.v.6n.3p.1

\begin{abstract}
The vast literature on discourse analysis includes many studies which investigate different types of texts and attempts to identify the properties that characterize them. The present study proposes an analysis of the narrative aspect in decoration discourse with the aim of revealing the textual features and organization that are uniquely utilized by this type of discourse and to clarify facets of similarities and differences from traditional narratives. The study explores the utilization of the problem-solution pattern and the goal-achievement pattern to communicate the intended message. Language with its pragmatic aspects plays an essential role in the construction and interpretation of such narratives. The database includes a variety of narratives extracted from different decoration and household magazines. Sharing experiences through narratives serves a broader function of establishing certain norms and standards to be followed by the majority of the population. By abiding to these norms, individuals strive to be affiliated to a particular social standard; the one intended by authors and publishers of these magazines.
\end{abstract}

Keywords: discourse analysis, decoration discourse, textual features and organization

\section{Introduction}

Throughout the literature on narrative, there has been a wide disagreement about the precise definition of a narrative. In its primitive form, a narrative should encompass an action and a protagonist. A narrative could be very broad including classical fiction, gossip columns, or accident reports or it can be restrictive to stories about past events. Reissman views "Narrative" as an encompassing term of rhetoric, whereas "story" as a limited genre. He further stated that "Genres of narrative with their distinctive styles and structures are modes of representation that tellers choose." (1993: 18). A narrative text should contain narrative clauses and should have a beginning, middle and an end. The shortest narrative could be made up of two clauses ordered temporally. Theorists adopt varying approaches to narratives. Scholes, for instance, who favors the structuralist view focusing on order and continuity, defines narrative as "the symbolic presentation of a sequence of events connected by subject matter and related by time" (Scholes, 1981:205). Similarly, Labov (1972: 360) confirms that a narrative arranges past experiences in a temporal order, which if reversed, the original meaning will be altered. On the other hand, According to Burner, narrative is "world making". His aphorism is that "Narrative imitates life, life imitates narrative." (2004:692). He asserts that the narrator structures his or her experience "in a manner that gives form to the content and the continuity of the life." (Burner, 2004:701).

Decoration narrative partially deviates from other types of narratives. Unlike the "narrative emplotment" suggested by Barwell (2009:52) and the "narrative connectedness" suggested by Currie (2006:310) where the consecutiveness and causality of events are a necessity to form an intelligible coherent whole, the occurrence of one event in the narrative of decoration discourse does not always entail another. The sequence of events is presented as a transformation from one state of affairs to its opposite. Decoration narratives flout expectations about storytelling and fits into the broader account of narrative. They seem to stand somewhere between the historical novel, futuristic fantasy and autobiography. They accord with the abovementioned definitions as there are temporal junctures among the different clauses. Yet, the altering of the temporal sequence would not affect the semantic interpretation of the whole text. They also represent life and reveal the owners' social and moral identities.

However, the events in decoration narratives do not report dangerous happenings but unusual actions in the sense that transforming a place from an unrecoverable previous state to a fabulous habitual one is not common to every one. As such it can be categorized as a resolution narrative. Decoration narratives can similarly be classified using Reissman's (1993) term as a "habitual narrative", where there is no peak in the action or as "topic-centered" narratives which refer to snapshots of past events that are stitched together thematically rather than by time. However, Labov's (1972) "temporal sequence" can still be witnessed in the structuring of the narrative as a whole due to the presence of temporal conjunctions as (first, second, then, when, after, before, later). The narrative in the data analyzed is a representation of subjective experience which is embedded in a whole text that also includes non-narrative parts. These non-narrative clauses are identified by Labov as "free clauses" that do not belong to any temporal juncture and can be moved freely without affecting the temporal order of the text. 
The paper adopts a qualitative approach to the written narrative texts from widely distributed household magazines. It attempts to show the properties and conventions that characterize decoration narratives. This is achieved by focusing on two major aspects in decoration narrative: interaction and design. The former is concerned with the different ways by which the writers communicate with their readers and the linguistic means utilized for this purpose. The latter refers to the structural organization of the narrative. According to Coste, "Narrative is neither a language nor a chain of events but a particular manner of imposing design on a presented world and of presenting worlds through the operations required by the constraints of this design." (1989:206)

The aim of the authors of the narratives in the decoration magazines is to lay claim to innovative ideas in the field of decoration and to acquaint future readers with the experience of house decoration. This is achieved through the structural organization of the text itself. In addition to the specific choice of language and the use of cohesive and coherence devices, the writers utilize the problem-solution pattern and the goal-achievement pattern to fulfill their purpose. By presenting the problems that other couples experienced and their solutions, the writer shares in minimizing the number of problems that future couples might experience in decorating their homes. The readers' purpose, on the other hand, is to gain insight into the latest developments and to keep abreast of such developments in order to be affiliated to a particular social class or to acquire the knowledge and ideas needed to improve and decorate their houses.

\subsection{Data}

The data for this study consists of 30 texts randomly selected from 11 different decoration magazines. The narratives extracted from different house hold magazines are located in special sections entitled "Real homes", "People and house" "Readers' home" "Inspiring homes" and "Country homes". Each of the texts focuses on the narration of people's experience in house decoration and innovation. All of the texts are approximately the same length. They occupy four to five pages two thirds of which are pictures and the texts fluctuate around these pictures. The number of the texts columns varies according to their location with respect to the pictures.

Decoration magazines make the interactivity visible on the page through the interplay of narratives and images. Readers' engagement with pictorial narratives is examined by Nanay (2009) who defines a narrative picture as one that "... tells a story, which supposedly means that it represents a narrative." (120). Based on the fact that a narrative necessitates an action, i.e. someone does something, Nanay (2009:124) asserts that not every picture is a narrative. In the distinction made between narrative and non-narrative pictures, the writer reached the conclusion that the former refers to the representation of action in the picture, whereas the latter refers to the ones representing a state of affairs, for example, a still life or a portrait. Though pictures in the narrative of decoration discourse represent one state of affairs either prior or after the decoration takes place, yet, there is symmetry between the written and pictorial narrative. Pictures vividly illustrate the end results of actions taken in the narrative. Nanay (2009:124) confirms that "The actions we are aware of while engaging with pictorial narratives are likely to be goal-directed actions."

Narrations in the analyzed data are carried out through several anonymous narrators who get in contact with different owners. The owners narrate what they experienced in decorating their houses. Their comments and tips of advice are occasionally presented in quotes that are prevalent throughout the text. In addition, the writers also narrate their own experience with the place that they see and describe. The immediacy of the descriptions and the closeness of the narrators to the event guarantee the truthfulness and vividness of what is being narrated.

\section{The framework}

The integrated framework adopted is that of Hoey (2001), Labov (1972) and Burner (2004). Hoey's framework is found to be essential in revealing the type of interaction existing between the writers and readers of this type of discourse. Labov's framework aids in identifying the internal structure of the narrative. Burner adopts the constructivist approach to narrative.

Hoey's (2001) textual analysis determines the hierarchy, patterning and interactional aspects of the texts under consideration. The interactivity between the text and its readers is a fundamental fact without which the reader might lose interest and abandon the text completely. The author anticipates that the reader of any text type will approach it with a series of questions. To fulfill the interactive aspect, the author keeps an eye on the readers' needs, formulates the readers' questions in his/her mind and provides answers throughout the text. Hoey states that "the writer's words activate knowledge in the mind of the reader which the reader brings into play in his or her interpretation of the text."(2001:120). Once the reader realizes that the text accords with his formulated expectations then the notion of interactivity is achieved. However, the readers' expectations are not consciously formulated as questions for Hoey asserts that "but that we do have expectations is demonstrated every time we are surprised or disconcerted by the direction a text takes."(2001:23)

Hoey classifies two levels of expectations: higher and lower. The higher level is concerned with expectations that the reader forms about the text as a whole. This is established by the location of the text in a particular place as a household magazine. Encountering the decoration text in this type of magazine and based upon their experience with similar types of texts, the readers expect to read about others' experience in decoration, get acquainted with the latest styles and take tips of advice. Expectations about the text as a whole can also be reached by reading the headline, the opening paragraph of the text or even by looking at the accompanying pictures which serve as a paralinguistic aid. At the higher level, episode boundaries mark the change of time, place, characters, structural transition and structural parallelism. The accumulation of several boundaries results in Hoey's hierarchy of the text as a whole, thus "Episode can be seen as resetting the narrative, adjusting the original settings in accordance with the narrative's needs."(2001:64) On the other 
hand, the lower level is concerned with expectations at the clausal level. Sentences are expected to relate to preceding and following sentences by reliance on various techniques as coherence, matching relations, sequencing and pairing. Accordingly, the writer has to anticipate the readers' expectations at the lower and higher levels.

The identification of features peculiar to decoration texts is based on implicit comparison with the basic narrative structure identified by Labov (1972) to reveal the design with which these narratives are presented. Labov (1972: 363) confirms that "A fully-formed narrative may show the following 1 . abstract 2. orientation 3. complicating action 4.evaluation 5. resolution or result 6. coda." The abstract summarizes the narrative in one or two clauses. The orientation identifies the time, place and characters and their activities. It also presents a whole view of the situation. The complicating action focuses on the sequence of events or what actually happened. Within the evaluation, the narrator expresses his feelings and comments on what happens. Evaluation devices are distributed throughout the narrative and are of equal significance as the narrative clauses. The resolution or result section refers to what finally happened. Finally, codas close off the sequence of complicating actions and indicate that none of the following clauses is of relevance to the narrative. Both Labov and Hoey agree in their views of narratives as a series of answers to underlying questions. The abstract answers the question "What was it about?" The orientation section answers the questions "Who? When? What? and where?" the complicating action is concerned with the question "Then what happened?" The evaluation answers the question "so what?" and the result answers the question "what finally happened?"

Hurdley (2006) and Souto-Manning (2014) views are consulted to investigate the role of narratives in sharing experience and constructing identities. Souto-Manning (2014: 162) asserts that narratives are ways of exhibiting experience and feeling. "Personal identities are constructed and (re)conceptualized as we share our narratives." In an attempt to highlight how the material culture of consumption is evident at home, Hurdley analyses the narratives made by owners around the objects placed on the mantelpiece at their homes. He concludes that "By constructing narratives around visual productions in the apparently private space of the home, people participate in the ongoing accomplishment of social, moral identities." (Hurdley, 2006:718). Hence, by analyzing the narratives in decoration discourse, the paper highlights certain social and cultural interests prevalent in the European societies.

\subsection{Interaction in decoration texts}

According to Hoey, text is an interaction between four persons. The author authorizes the text and takes responsibility for what the text attempts to do. The writer composes the text and is responsible for its language. The audience refers to the imaginary readers who the writer addresses and whose questions he attempts to answer. Finally, the reader is the one who reads, understands and benefits from the texts. Prior to the writing process, the writer has a certain kind of reader in mind. However, the audience targeted in decoration discourse varies. They are mainly adults, who can be interior designers, with specialist knowledge in the field, couples, single males or females, or even housewives who have previous or no knowledge in the field of decoration and who want to learn.

\subsubsection{Questions and Answers in Titles}

Before reading the text or even the headlines the readers formulate their expectations the moment they encounter the pictures that fill more than two thirds of the page. The titles and subtitle presenting a summing up at the beginning of the text also invites the readers' interaction. Examples are as follows:

"SEASIDE DELIGT: Moira and Stuart have turned a dilapidated wooden chalet into a cozy Cornish retreat inspired by the elements.”(House Beautiful, June 2002: 27 - 30)

"OPEN SESAME: When Rachel and Alex Parks-Szymborski bought a run-down, crammed flat they knew what to do - open it up and let light flood in"(House Beautiful, May 2002: 2528)

"PARADIZE FOUND: When Stephen Phillips bought his Plymouth flat two years ago, it was in dire need of renovation. But within six month, he'd created a seaside haven." (House Beautiful, May 2002: 37-40)

These titles and subtitles set the readers' expectation with regards to the text and its direction. The best way as Hoey (2001) believes, for the writer to be able to identify the readers' needs is by asking a series of questions, the answers to which are provided by the text as a whole. Questions play a major role in Hoey's framework as they mark connections between sentences and explain the relation between a sentence and its context. Among the questions that the writer hypothesizes to be going on in the readers' mind and to which the decoration texts provide answers are:

"Who lives there?" "What is the house like?" "What is it worth?" "What are the steps carried out to restore the house from its awful state?" "What is the owner's style?" "What made the couple buy a run-down, cramped flat, a daunting, derelict cottage, a ramshackle place?" "How is it possible that a cow's barn become a house for people?" "How did they manage to make these drastic transformations?" "What are the steps followed to transfer these unacceptable places to a paradise, a haven, a dream house, and elegant, stylish and vibrant homes?" "From where did they buy or get the different objects?" 
Underpinning decoration narrative texts is the interactive question "What did they (the owners) do next?" which is equivalent to the question "and then what happened?" which characterizes the sequencing in fictional narrative. The readers' expectations do not simply stop after reading the headlines which motivate higher expectations, but proceed from one sentence to the other as each new sentence raises expectations in the readers' mind. This can be illustrated by an example from the data analyzed.

"You have to step inside the home of knitwear designer Debbie Bliss to know she's got an eye for style and a passion for colour.”(House Beautiful, June 2002: 34 - 38)

These are the first lines that the reader encounters in the narrative article entitled "THE PERFECT MIX". Interaction between the reader and writer is the first step towards designing the decoration narrative as a whole. The writers' hypothetical questions are the guidelines upon which they build their writing. The answer to the questions are usually scattered all over the text. This is usually a privilege for readers searching for the decoration of specific rooms, as they can select the sections to be read. Interaction is first carried out by the readers' aroused expectations since they want the text to answer major questions as:

"What are the colors that she used in her house?" "What style is her house?" The reader expects answers to these questions which are deterred. The writer pursues the opening lines with information about the owners of the house and their careers. It is usually in the third paragraph onward, that the readers' expectations are met. The house is reintroduced and a quote from Debbie's speech connects the third paragraph with the opening lines "it's a strange mix of styles which reflects our personalities and interests". Repetition of the terms "mix" and "style" partly establishes the coherence of the text and fulfills the reader's expectations with regards to the question "what style is her home?" Moreover, this same sentence triggers other questions in the readers" minds as in "what are their interests?" The answer to which is immediately provided in the following sentence "I'm into color and texture, while Barry is passionate about the past and is an avid collector of period pieces." Thus the readers' series of questions move on from one part of the text to the next inquiring about each room separately 'what did they do next?' and the writer keeps up to the readers' expectations by exhibiting each room elaborately including the walls, floors and furnishing pieces. However, some sentences flout the readers' expectations by containing an element of surprise as in

"As soon as she laid eyes on the 250 year-old-barn, complete with cow's dung, rats and spiders, she knew it was what she had been looking for." (25 Beautiful Homes, May 2002: 40)

The enumeration of several negative aspects of the approaching house provides an element of surprise and flouts the readers' expectations. The reader expects the buyer to turn his back but contrary to his/her expectations, s/he realizes that these characteristics did not hinder the buyer but were the exact characteristics she was searching for. Such astounding statement is intended to arouse the readers' interest to read the text and know more. It raises a number of questions in the readers' mind as why would someone be in a need for such a dungy place? However, the negative aspects in the opening lines contrast with the fabulous pictures accompanying the text and showing the final results of the decoration process. Similarly, in "Bank Statement: Martin Ball transformed a former Dartmoor bank into a small but characterful home and art gallery." (25 Beautiful Homes, May 2002: 20) The surprising element in this headline refers to the difficulty of transforming a bank with its internal cells, steel reinforced and bombproof walls into a stunning home. These challenging headlines are intended by the writer to communicate the message that no matter how dreadful or irreparable your home might be, it could not ever reach the degree of dreadfulness and irreparability described in the article, it is always possible to transfer it to something appealing.

\subsubsection{Informality and intimacy}

Interaction with the reader is also evident in the direct and informal way of address to the reader as seen in "but step inside Simon and Jakie Mc Laren's home" (House Beautiful, May 2002:18) "you have to step inside" (House Beautiful, June 2002: 34) and "welcome to the house of fun" (Real Homes Magazine, April 2001: 54).

These instances sound like an invitation to enter where the narrator will show the reader around the house. The reader is treated as a friend and the writer is telling him the latest news about another close friend to whose house the reader is invited to roam and investigate every single detail. Informality of style in addressing the reader is a prominent feature of this type of discourse. This is evident in the constant use of the pronoun "you" to address the reader directly and indicate intimacy. It also invites his participation in the discourse as an active reader who will match the owner's experience with his own, or who after reading these articles would have the initiative and take certain measures to renovate or remodel his home. For example

"After Emma and Michael Kirby tell you what they've done to their house, it's hard not to wonder why on earth they bought it in the first place." (Ideal Home, June 2002 p. 48)

In addition to the personal pronoun "you," the utilization of the verb "tell" as opposed to "narrate," "inform" or "acquaint" creates a friendly atmosphere wherein the owners will impart and disclose every detail to the reader. The personal pronoun "you" is often used in an inclusive sense. That is referring to the narrator and the reader. For example 
"There's nothing more annoying than not being able to put a sofa where you want because you'll be covering up a valuable plug point." (Ideal Home, June 2002 p. 50)

In this example the two instances of the personal pronoun "you" implicitly refer to the first person singular pronoun "I", namely the narrator or the owner. However, to maintain this intimate relation with the reader, the narrator resorts to the pronoun "you" in order to imply that what applies to me as an experiencer is sure to apply to you as readers. The personal pronoun "you" is also constantly used to give tips of advice to the reader as in

"You can buy the best paint, but if you haven't got someone to prepare the walls properly and who isn't meticulous about the work, it won't end up looking right.”(Ideal Home, June 2002 p. 53) And

"If you can find bigger items in sales, then you can save money to spend on the things you really love - in my case, Osborne and little fabrics.”(Ideal Home, June 2002:77)

"You can learn by trial and error and by simply not being afraid to have a go" (Inspirations For Your Home, July 2001:47)

Intimacy and interaction is also evident in the sense of humor that some narrators exhibit. E.g. a narrative is enunciated by how the owner came across his new home. It happened accidentally; as he was going to buy baked potatoes for lunch he saw the bank with a "For Sale" sign. He made a deal over the phone to buy the bank then he proceeds with his narrative by saying "and I returned to lunch with the baked potatoes and the bank!" (25 Beautiful Homes, May 2002:21)

Informal and idiomatic expressions that are often used in spoken discourse are also evident as a remarkable feature of decoration discourse. For example "Why on earth" (Ideal Home, June 2002 p. 48) "set their hearts on" (House Beautiful, May 2002: 25) "it wasn't all plain sailing”(House Beautiful, June 2002:30) "Chris had a brainwave"(Ideal Home, June 2002: 66) "back-breaking work" (The Real Homes Magazine, April 2001:51) "I like to think we've put the house back on its feet." (The Real Homes Magazine, April 2001:14) "The garden wall was the last eye sore" (The Real Homes Magazine, April 2001:20 ) "But it was having the new floor laid that was the icing on the cake" (House Beautiful, May 1999:42) "Anything new and shining would have stood out like a sore thumb." (House Beautiful, May 2002:32)

Shared understanding is a sign of interaction between the writer and his readers. This is evident in the writers' use of borrowed lexical items that they anticipate the readers to be acquainted with. This feature is peculiar to decoration discourse and is exemplified in: 'toiletries' 'maisonette' 'papier mache' 'frottage' 'terracotta' other peculiar compounding is evident in "easy-facing room" and "distressed furniture"

Relationship between clauses in a text is another aspect of the interactivity of the text. If the amount of inference made by the reader is reduced to a minimum, this means that the writer is giving the appropriate signals for the reader to understand the text. Thus the text can be judged as being interactive. The two types of clausal relations identified by Winter (1994) are found to mark the interactivity of the decoration texts.

\subsubsection{Matching relations}

Narration of the decoration process passes through unordered sequences. They generally start from the basement and up till the top floor. However, if the order is altered it would not affect the coherence and understandability of the narrative. Two types of matching relations exist in the data-corpus under scrutiny

(a) A matching relation of contrast exists in all the texts analyzed by presenting the previous state of the house prior to the decoration process. This is usually presented in one or two sentences and often the headline. Contrast with this clause is carried out at 2 levels. The first is at the level of the text as a whole where the main clause contrasts with several clauses presenting the changes carried out during the decoration process and providing partial solutions to the big problem. On the second level, this clause also contrasts with the final result reached at the end of the article after the decoration has been completed. The opening lines of one of the analyzed texts read as follows:

"Rachel and Alex Parks-Szymborski set themselves a tough challenge when they bought their one bedroom flat in south west London. They were on the search for a spacious and light-filled home but settled instead for a property that was dingy and cramped. 'When we first view the flat we weren't impressed', says Rachel. 'It looked really small and was far from what we were looking for. But there was a lot of light coming into the rooms and we realized that if all the old fittings were removed, there would be a reasonable amount of space to work with.”(House Beautiful, June 2002: 25)

A global contrast is first set between the "dingy" "cramped" state of the one-bedroom flat and the fabulous pictures occupying two third of each page and showing the final result of the decoration process. Contrast is also established between the owners' feelings at the opening of the narrative "we weren't impressed' 'it was far from what we were looking for' and at the end of the text 'Rachel and Alex are both delighted with the way things have turned out.' And 'But they're thrilled with the end result.' (House Beautiful, June 2002: 27) 
Matching relation of contrast is also witnessed at the clausal level where "spacious" contrasts with "one bedroom-flat" in the previous sentence and "really small" in the following sentence. Also in "Although the rest of the place was a mess, the bathroom was in pretty good condition." The subordinator "although" as well as the contrastive adjectives "mess" and "pretty good" signal a matching relation of contrast.

(b) Another type of matching relation in decoration narrative is that of repetition and paraphrase. One clause is repeated or paraphrased several times throughout the text. The narrative texts exhibit features of coherence which is maintained through the cumulative effect of each episode and its direct or indirect relevance to the headline and subtitles of the text. In addition to marking interactivity in texts, matching relation aids in the establishment of coherence through out the narrative. For example

"we realized that if all the fittings were removed, there would be a reasonable amount of space to work with." (House Beautiful, June 2002: 28)

The fittings to be removed were not made elaborate at this stage. However, further repetitions and paraphrases of the same sentence reveal that 'fittings' refer to 'walls.' The knocking down or removing of the walls is repeated seven times in a text of 170 lines. Repetition of exact quotes is used twice in two different paragraphs. 'We knew we wanted to knock down the wall between the kitchen and what was the bedroom to make an open-plan living area.' And 'we knew the best thing to do would be to knock down the wall between the kitchen and what was the bedroom." Further, paraphrase of this statement is evident in "we made a conscious decision to break up the two areas." And "to continue the theme of the two spaces" where the two areas and the two spaces refer to the bedroom and the kitchen mentioned earlier. Later, the same theme continues in "he agreed to come and stay while we fitted the units, knocked down the wall and ...." And finally in "we knew right away that knocking down the wall was the right decision."

Another aspect that aids in the establishment of coherence in the text is the relationship that exists between the headline and parts of the text. Often, certain lexical items that are contained in the headline are repeated or paraphrased in the text itself. This is evident in "At Home with Heartbeat's Tricia Penrose." (Homes and Ideas, July 1999:44) The use of the possessive in the headline is striking unless one is culturally acquainted with the fact that Tricia Penrose is an actress and Heartbeat is a series in which she has made her name. This is revealed from the text itself where the subtitle reintroduces Tricia Penrose as "actress Tricia Penrose, better known as Gena Ward in the popular TV series." Still heartbeat is ambiguous especially when reused in the opening line of the text "Tricia Penrose's Heart Beat a little faster when she first saw the house which was soon to become her new home." In the headline "Heartbeat" is used as a compound noun but in the first line the writer plays on the word "beat" and uses it as a verb for the subject "heart", yet maintains the upper case for the two words to alert the reader to the intended play on words. It is only at the end of the third paragraph of the text that the reader is reassured that Heartbeat is the name of the series the writer utilized to show the amount of the excitement felt by the owner on first encountering her house. "They met three years ago when Kevin started filming for heartbeat." Further reference to heartbeat is made in the $10^{\text {th }}$ and $11^{\text {th }}$ paragraphs. "When she is not decorating, Tricia is busy with Heartbeat, a role that she enjoys." And "I couldn't do it because of my commitment to Heartbeat." These various repetitions of a single lexical item present in the headline aids in maintaining the coherence of the text as a whole.

\subsubsection{Sequential relation}

Like matching relation, sequential relation exhibits an interactional function in addition to its role in the structuring and organization of the decoration text. Winter (1994:52) states that "the logical sequence relation is concerned with representing selective changes in a time/space continuum from simple time/space change to deductive or causal sequence which is modeled on real-world time change.

A dominating sequential relation that is evident in all the texts analyzed is that of result. "She had seen a picture in a magazine of a shaker-style kitchen so we took the old pine carcasses and I made MDF doors and drawer fronts." (Inspirations For Your Home, July 2001:38) "I like to feel really homely and comfortable, so I go for warm, natural colors, Period and Shaker ranges in particular."(Inspirations For Your Home, July 2001: 47) "The ceiling was about seven feet high so I needed to dig the floor down by a foot......We also put in newel posts next to the sink and stove, to add interesting structure." (Inspirations For Your Home, July 2001: 38)

In these instances the speakers present a situation they felt or encountered during the decoration process. The sequential result is then marked by the sequential clause relation of result "so." The result is usually a logical consequential action based upon the situation presented. Sometimes the situation itself signals a problem as in "The ceiling was about seven feet high so I needed to dig the floor down by a foot." And "It had a paint-effect wallpaper which Mathew hated so, finally, inspired by a photograph in a magazine showing a French chateau where the walls were stone paneled, Isabel asked David Thomas to produce something similar." The solution to the problematic situation presented by "seven feet high and "hated the wallpaper" is immediately provided by the result clause enunciated by the conjunction "so".

Another dominant sequential relation in decoration narratives is that of reason and is marked by "as", "for" "because" and "to" as in: 
"Jo chose a combination of soft blue and lilacs because she wanted them to feel calmed at the end of the day....... like to feel really homely and comfortable, so I go for warm, natural colors, Period and Shaker ranges in particular." (Inspirations for Your Home, July 2001: 46 - 47)

We also put in newel posts next to the sink and stove, to add interesting structure..... We think this must have been scullery because we found a smashed stone fire surround and an old Belfast sink." (Inspirations for Your Home, July 2001: 38)

"We chose a glass table from Ikea as it doesn't take up too much space and fits in with the oriental theme.”(House Beautiful, June 2002:22)

The speaker utilizes this type of relation to justify the reasons that led him to carry a particular action.

\subsubsection{Mixing the two relations}

In addition to several clauses signaling matching relations or logical sequential relations, some clauses exhibit a mixture of the two types, for example

"When Ed and Sarah moved in, the house was not looking its best. It had been empty for 12 months and had suffered some damage as a result of a break in. 'But apart from that and a small case of damp, it was fine,' says Sarah.”(House Beautiful, May 2002:32)

The negative "was not" signals a denial of the old state on which they found the house. This denial is however partial as it negates the gradable adjective "best". The following complex clause provides an elaboration by indirectly stating the reasons why it was not looking its best. This is achieved by the use of several negative lexical items in 3 clauses as "empty" "suffered" "damage" and "break in." The first two clauses are coordinated whereas the third exhibits an elaborate logical sequence of cause/effect where the cause "break in" led to the effect "suffer damage." The following clause exhibits a matching relation of contrast to the previous clause marked by the coordinator "but" and "a part from." The reader expects a positive continuation to follow and which states the reason that convinced them to purchase the house. This complex clause sums up the denial mentioned in the two previous clauses by using the demonstrative 'that' which refers back to all that was mentioned. The coordination of another aspect of the house completes the negative picture that the writer wishes to convey and which is immediately followed by the single positive aspect "it was fine."

\subsection{The design of narrative in decoration discourse}

Design in decoration discourse refers to the hierarchical organization, the structure and the predominant patterns in this type of discourse. The hierarchical organization of decoration narrative is found to be based upon five building blocks.

\section{Abstract}

2. The orientation section

3. Planning

4. Decorating process

5. Final result

The aspects of the narrative structure derived from Labov's (1972) framework are elaborated in the narratives under scrutiny. However, there are slight differences that will be discussed regarding each aspect. The problem-solution pattern and the goal-achievement pattern are found to intermingle with the building blocks of the narrative. These patterns have a structural effect in the organization of the narrative similar to that of the hierarchical organization. Both are found to recur in the data analyzed with great frequency.

The goal-achievement pattern commences at the planning building block and proceeds through out the decoration process and the final result blocks. The problem-solution pattern encountered in decoration narratives can be classified as major and minor. The major problem refers to the state of the house prior to the decoration process. It is usually located in the subtitle or the first lines of the article. The solution to which is provided at two levels. First the solution can be provided in the same subtitle along with the evaluation and the accompanying pictures. Second, the detailed solution is presented in steps throughout the text till the positive result is reached in the last paragraph of the text. In addition to the major problem, several minor problems that the owners face during the decoration process with their immediate solutions are presented in the decoration process block.

The first two building blocks overlap in that the orientation section in any narrative sets the ground for the narrative by introducing the characters, time and place. However, in decoration narrative the participants and place are presented in the headline and the first subtitle; that is in the abstract. Further information about the place and the owners is later provided in the orientation section which can be in the first or second paragraph. 


\subsubsection{The abstract}

The first block in the hierarchy is the abstract. Abstracts in decoration texts are presented in the headlines and the subtitles. The first instance where the problem-solution structure intermingles with the narrative's building blocks is evident in the subtitles. Similar to all titles and subtitles, those of decoration narratives are characterized by having a summing up function. They serve an important communicative function in the narrative in that they acquaint the readers with what the narrative is all about and motivate them to proceed with the narrative in order to know more details. In addition, the subtitles of this type of text are peculiar in having a commentary and evaluative function. As such, they contain the four major elements of the problem-solution structure as identified by Winter (1977) namely that of situation, problem, solution and evaluation. Each subtitle provides a global view on the text by stating the problem, solution and evaluation. At other times, the problem is stated while its solution is implied by looking at the photos, without even reading the text.

Winter (1977) exemplified the problem-solution pattern by an artificial text of four sentences where each sentence refers to an element in this structure. Hoey (1994) however, objects to this example as being artificial and limited. He believes that this structure is never to be found in such limited contexts but is usually extended over longer stretches of discourse. In addition, he objects to the fact that the pattern does not usually follow these steps strictly. Often the pattern consists of a situation within which there is a problem. If there is a solution to the problem it can be presented as a positive evaluation, a positive result or both. If there is no solution to the problem; that is to say, there is a negative evaluation, then recycling occurs in the problem solution pattern and the problem returns to the point from where it started.

By examining the problem-solution pattern and applying it to the narratives analyzed, it is found that each subtitle provides a summing statement of the text which is a miniature of the problem-solution structure. This structure begins at a point where the reader encounters certain signals of a problem that invites solution. Among these signals is the word 'Problem', negative evaluation of the situation by using negative lexical items and real world matters that are often regarded as problematic. Within the subtitles, the problem-solution structure is identified by the presence of different lexical signals each referring to an element within this structure. This is evident in:

"Martin Ball transformed a former Dartmoor bank into a small but characterful home and art gallery." (25 Beautiful Homes, May 2002:20)

"It took Debbie Wolff five long years to transform a derelict barn into a luxurious home - but the results have been worth it" (25 Beautiful Homes, May 2002: 40)

"The Lawrences have spent more than 20 years expanding their two-bedroom bungalow to create a spacious five-bedroom house" (25 Beautiful Homes, May 2002: 66)

"A pigeon-infested warehouse has been transformed into the stunning home of Nick Lowden and Gill Mc Givern"(Country Homes and Interiors, July 2001: 42)

"The cottage was derelict with ivy growing out of the chimney and cows wandering in and out" (House Beautiful, June 2002:42)

The situation as is the case with all the articles is that of transforming the place from its previous undesirable state to a more desirable one. The problem is that the place to be transformed is a "bank" with its steel reinforced and bombproof walls, "a pigeon-infested warehouse" "a derelict barn" and "a two-bedroom bungalow" and the challenges of transforming these places into homes. The solution is implied from the use of the past tense verbs "transformed" and "expanded" which means that the mission is accomplished. In addition, the fabulous pictures accompanying the text provide a vivid nonverbal solution. The evaluation is evident in the use of the positive adjectives "characterful" and "art gallery" "stunning" "spacious" and "luxurious."

The technique used for titles vary from one magazine to the other. However, they are all marked for their distinctiveness from titles of stories, fairy tales, novels, and newspaper reports. Four different types of titles are noticed in the articles under scrutiny. They are generally concise made up of two words with the exception of the second type.

The first type is remarkable for its alluring titles. It invites the readers to establish a relation between these titles, to which they are previously acquainted through their knowledge of famous sayings, films or T.V. series and the text to be read. E.g "Open Sesame"(House Beautiful, May 2002:25) "Back to the Future" (House Beautiful, May 1999: 39) "Paradise Found"(House Beautiful, May 2002:37) "Love at First Sight" "(House Beautiful, May 2002:31) "Beautifully Bold" (Inspirations For Your Home, July 2001:38), "Living on Top of the World”(The Real Homes Magazine, April 2001:71) and "Turn the Clock Back in Style" (The Real Homes Magazine, April 2001:17) 
The second type of title is based on direct speech quotations extracted from the owners' speech. This type is characterized by its subjectivity through the constant reliance on the first person singular or plural. As such intimacy and friendliness can be felt in these titles. The narrators are inviting the readers to tell them their story in an intimate and close manner. For example,

"Cows used to live in our farmhouse."(The Real Homes Magazine, April 2001:104) "We designed every last detail of our dream house." (Ideal Home, June 2002: 46) "Our style has completely changed" (Ideal Home, June 2002: 55) "We think the house likes being a family home again."(Good Homes, Dec./Jan. 2002: 60) "As soon as I saw the details I knew it was the house for me." (Good Homes, Dec./Jan. 2002:105)

A third type is of a commentary nature where the writer provides his own evaluation as in "The Perfect Mix" (House Beautiful, June 2002: 34) "Lucky Strike" (House Beautiful, June 2002:19) "Perfect Teamwork" (Inspirations For Your Home, July 2001: 44), “Clear Vision” (25 Beautiful Homes, May 2002: 6) "Period Gem” (25 Beautiful Homes, May 2002: 72) and "Tailor Made." (25 Beautiful Homes, May 2002: 77) This type relies mainly on an attributive adjective preceding the noun and voicing the writer's evaluation of the end result of the decoration process. As such all the adjectives used are positive. In addition to adjectives modifying nouns, other possibilities in these titles are the coordination of two adjectives or a compounding of a noun and an -ed participle.

The fourth type though confined, presents plain titles like the ones encountered in novels as "Toils and Stripes" (Country Homes and Inspirations, July 2001:70) "The necessary things in life" (Country Homes and Inspirations, July 2001: 40) "A family home"(25 Beautiful Homes, May 2002: 12) and "Swedish Pastoral." (Country Homes and Inspirations, July 2001:22). These titles concisely reflect what is to be discussed in the narrative.

However different the titles might appear to be, the subtitles following these titles share common characteristics. First, they introduce the characters or participants in the narrative, namely, the owners using first and family names. Second, they usually have a similar structure. They begin with a time clause enunciated by the pro-form "when" to denote a boundary of time. It indicates the point from which that time is measured. "When (naming the characters) .." If this is not the case in the subtitle, then it is in the opening lines of the narrative. This structure is intended to usher the reader to the point from which the narrative starts, that is, the time when they bought the house. The adverbs "after" and "before" are also utilized to refer to the temporal sequence in the narrative but "when" is more recurrent. This is evident in:

"When Rachel and Alex Parkers Szymborski bought a run-down, cramped flat they knew what to do - open it up and let light flood in.”(House Beautiful, May 2002: 25)

"The attraction was instant when ED and Sarah Clark saw their house for the first time- the former estate cottage is now a comfortable country home." (House Beautiful, May 2002: 25).

"When Gillian Willson and her American husband Al first started looking for a property near her parents in Suffolk, Gillian had her heart set on a period rectory." (25 Beautiful Homes, May 2002: 7)

"When Stephen Phillips bought his Plymouth flat two years ago, it was in dire need for renovation. But within months he'd created a seaside haven" (House Beautiful, May 2002: 25).

“After Emma and Michel Kirby tell you what they've done to their house it's hard not to wonder why on earth they bought it in the first place." (Ideal Home, June 2002:48)

"Thirteen years after they bought their four-bedroom house in a near-derelict state, Dorothy and Chris Strickland finally feel that it's more or less exactly as they want it, despite their differing tastes." (Ideal Home, June 2002:65)

\subsubsection{The orientation section}

This block sets the ground for the following blocks by reintroducing the participants, place and the problem that were slightly mentioned in the headlines and the subtitles. Occasionally, however, information that is relevant to this block can be seen in other blocks as the planning or the decoration process blocks. Within this part the writer re-introduces the participants in the discourse (in this case the owners). He gives brief information about them; their background, tastes and interests and the state upon which the couple bought their house, which is the problem. The content of most narratives focuses on someone who did something to another person at a particular time and in a particular place. However, the content of the orientation sections in decoration narratives generally focuses on the action that a participant exerted upon a particular place and which, to the participants' own satisfaction, caused change in that place.

The place is presented in general terms in the abstract and then with more details throughout the narrative. The place is usually the house, the flat, the mansion and the country house around which the whole narrative rotates. Along with the presence of authentic photographs covering the maximum space of the pages, the narrator provides every minute detail in his description to allow the reader to envisage every corner and every piece of furniture in the rooms described. This 
place is usually described in negative terms prior to the decoration process and in positive terms during and after this process. For example:

'Stylishly dull Victorian house.”(Inspirations for Your Home, July 2001: 38)

'the whole place was completely ramshackle.'(The Real Homes Magazine, April 2001: 17)

'it was a daunting prospect.' (The Real Homes Magazine, April 2001: 43)

'dingy and old fashioned carpets' (The Real Homes Magazine, April 2001: 49)

"The farmhouse had once housed cattle and was in dire need of major improvement." (The Real Homes Magazine, April 2001:105)

'it had been repossessed and condemned by the gas board.'

"The bathroom was literally just a wooden contraption hanging off the side." (The Real Homes Magazine, April 2001: 17)

Among the features of decoration narrative is a clear change of place. This is usually marked by a clause reporting arrival in a new place usually another room in the same house. The change of place from one room to the other marks the boundary of a new episode. For example:

"To minimize the mess, Lucy had the bathroom gulled at the same time as the kitchen" the following paragraph presents another area in the house. "When it came to the living room, Lucy was strongly influenced by her sister who had spent some time in China." The subsequent paragraph focuses on a new space "In the bedroom, Lucy went for a pretty look"(Ideal Home, June 2001: 105) the article then continues with vivid descriptions of the painting, the walls, floors ...etc.

A distinctive feature of narrative discourse is that there is no change in characters. Those usually introduced in the headline or the opening lines are the ones who carry out the action throughout. Besides being the first-hand narrators, whose voice the readers constantly hear, the writers' narration, comments and evaluations bolster the original narrative. The majority of the characters in decoration discourse are presented as having an artistic career or talents even if not directly related to home decoration. If there are exceptions we find that they require the help of experts in the field to help them in the decoration process. This is intended by the narrator to give weight to the decorations carried out and to assure the reader that the transformations carried out are achieved by experts in the field or those whose taste is reliable and trustworthy. For example 'Helen, a freelance textile designer' (House Beautiful, May 1999:39)

'As well as being a paint effect specialist, Jo is a whiz at making curtains .... While James, who has a business designing and making metalwork accessories, enjoys making furniture and tackling DIY projects.' (Inspirations For Your Home, July 2001: 44)

'She's an art director in a marketing firm and works with colors, designing leaflets and brochures.' (Inspirations For Your Home, July 2001:38)

As in fictional narratives, decoration narratives have a chronological and temporal sequencing of events the accumulation of which leads to the final conclusion. In decoration narratives reference is made to three periods of time. The first, prior to the decoration process, is relatively short. The second refers to the period where the decoration process takes place and this occupies most of the narrative. The third period is after the decoration is carried out and it refers to the final result in addition to the narration of the whole experience.

The time in decoration narrative is constant throughout and confined to the period where in the decoration process took place. For example

"It took two years before it started to resemble a home." (The Real Homes Magazine, April 2001:44)

"Work started at the beginning of January and was finished by the end of June."( (House Beautiful, June 2002:22)

"He bought it and within six months had transformed it into a stunning swish bachelor pad" (House Beautiful, May 2002:37)

\subsubsection{The planning stage}

This is usually the stage where the owners spell out their major goal and plans for transforming the unpleasant existing state to a new acceptable one. As such it is an embodiment of the goal-achievement pattern. Similar to the problem solution pattern there are major as well as minor goals. Underlying the major problem is the owners' major goal to exert change upon the place and transform the house from its deteriorated state to an acceptable and habitable one. This goal is spelt out in the planning block. Hoey argues that the components of the goal achievement pattern are situation, goal, method of achievement, evaluation and/or result. This pattern can be represented by the questions:

"What was the situation?" 
"What goal did x want to achieve?"

"What method did x or y use to achieve it?"

"How successful was this in the opinion of $x, y$, or $z$ ? What was the result for $x$ ?" (Hoey,2001: p.146)

The planning stage is found to occur in the second or third paragraph. Through this stage, the narrators inform their readers with the final result they wish to fulfill so the readers can follow the line of action "the method of achieving". The goal is either signaled by certain lexical items as "the project" "goals" "idea" "wanted" or it can be embodied in a whole statement as exemplified in the following quotes.

"The project was to get the house back to the way it had been built, taking down partitions and restoring the rooms as Shaw has designed them.” (The Real Homes Magazine, April 2001:8)

"John's idea for renovating the cottage was to open it all up, adding a conservatory at the back." (The Real Homes Magazine, April 2001:17)

"She wanted to live in something similar" (The Real Homes Magazine, April 2001:41)

"We had to pull the whole place apart and put it back together." (House Beautiful, May 1999:39)

"We knew what we wanted - simple rooms and plain walls with the bones of the original construction showing through.”(Ideal Home, June 2002:56)

"They were clear about their goals. 'We wanted a wide hall, lots of light, bedrooms with en-suite bathrooms and a big living space,' explains Emma who is an interior designer.” (Ideal Home, June 2002:48)

The achievement of the major goal is usually reached at the final result stage. In addition, minor goals run throughout the narrative and portray the owners' needs, desires, plans, ideas, the achievement of which follow in the subsequent clauses. Throughout the narratives, the owners' goals for inflicting a particular change on the place are spelt out. This is evident in:

"I wanted it to be inviting' says Sarah. To achieve this effect Sarah got timber from a scrap yard, which she stained and attached to the ceiling, to give the look of original exposed beams." (The Real Homes Magazines, April 2001:56)

"John wanted traditional colors and so asked his friend Patricia Gambling, an interior decorator, to do the paint effects.” (The Real Homes Magazine, April 2001:17)

"Mark wanted to keep an airy spacious feeling. He and Samantha achieved this by banning all clutter, sanding the floor and leaving it bare, and using blue fabric throughout." ( 25 Beautiful Homes, May 2002:48)

"He wanted an American theme to give the feel of a state side pool room, so he had a mural painted along one wall 'to give a real impact.' 'I've always wanted my own games room' he says so I decided to convert one of the spare bedrooms.' (Ideal Homes, June 2002:70)

From the previous examples, it is noticed that the goal is marked by the words "wanted" and "needed" whereas the achievement of these goals are marked by the lexical items "achieve" or the utilization of coordinate conjunction "and so" or "so." However, the utilization of the coordinate conjunctions to signal solution in the problem-solution pattern and to signal achievement in the goal-achievement pattern makes the two patterns overlap. Overlapping is also evident in an instance where the narrator spells out a goal but the achievement of this goal comes in a solution form.

"As the children got older Sarah saw the need for more space and her solution was to convert the loft into a bedroom for her and her husband.” (The Real Homes Magazines, April 2001:56)

The goal is signaled by "the need for" which can also be viewed as a partial problem the achievement of which is marked by the term "solution."

\subsubsection{The decoration process}

This stage is equivalent to the Episodic component wherein the actual happenings of a narrative take place. Similar to other types of narratives, decorative narratives is abundant with long descriptive paragraphs that acquaint the reader with every minor detail. The presence of authentic photos accompanying the detailed description of the decoration process adds vividness to the description. In addition, the descriptive paragraphs are abundant with modifications of nouns and noun phrases. One can rarely find an unmodified noun. Most nouns are modified by up to four or five adjectives and nouns, for example, "little carved wooden bedside tables" (Ideal Home, June 2002: 53) "cheap cheery cherry wood laminate" (Inspirations for Your Home, July 2001: 38)“misty mauve gloss picture rail" (Inspirations for Your Home, July 2001: 42) "Luxurious pale yellow blue and cream striped curtains" (Ideal Home, June 2002:68) "vibrant four bedroom family home" (Inspirations for Your Home, July 2001:38) "diamond - patterned Arts and craftsstyle sideboard."(Ideal Home, June 2002:68) "Cool duck-egg for the kitchen walls." (House Beautiful, May 2002:26) Due to the vividness of the description, all the readers' senses are found to be at work in this type of discourse. They feel, see, touch and smell the houses they read about. 
Throughout the narratives, reference is constantly made to places where the couples visited and which helped them fulfill their goal. Brand names utilized in decoration discourse serve a double function. They are first used to modify nouns, but to be understood as such, they require the shared cultural background between the readers and the writer as in "Belfast sink" "MDF doors" "Shaker-style kitchen" "Pistachio green by Dulux" "I found this fushia on sale in Habitat" "Natalie has combined the softness of Farrow and Ball's Cooking Apple Green on the high walls with the warmth of Crown Paints' Sash Red which immediately pulls her russet sofa into the color scheme". Second, brand names also serve as an indirect way of advertising.

The actual happening in the decoration process stage is mainly a representation of the major problem previously mentioned in the subtitle but with more details. In addition, other minor problems and their immediate solutions cover the utmost area of this block. The immediate solutions that occur with the problems in the same clause are attached to these problems by coordination, for example "I even had no toilet at one time and was forced to use my local pub." (The Real Home Magazine, April 2001:43)

"Louise was running out of money - fortunately for her she has some good friends and they stepped in to help with the back-breaking work." (The Real Home Magazine, April 2001:51)

"When they began, they had to keep to a tight budge, so Sarah tried to find inexpensive ways to do up the house." (The Real Home Magazine, April 2001:55)

"They hit another problem when they discovered that the conservatory floor was riddled with damp and had to be re-laid." (House Beautiful, May 1999:40)

"But the worst problem was the grey patterned tiles. Louis didn't have the budget or the know how to change them, so she had to come up with a scheme that would work with them." (The Real Home Magazine, April 2001:50)

"There had been nasty green-patterned lino on the floor and Louise decided to replace it with white Amtico flooring." (The Real Homes Magazine, April 2001:51)

In the above examples problems are marked differently. In the first three examples the problems are presented as realworld problematic matters. "no toilet" "a tight budget" "running out of money." In the fourth and fifth, the writer utilizes the word "problem" to indicate its presence. In the sixth instance, negative lexical item "nasty" indicates the presence of a problem. The solution to these problems are also signaled by the coordinator "and" or "so" followed by a model verb "had to" or action verb "forced" both of which indicate obligation.

In other instances, the problem is presented in a sentence and the solution follows in the subsequent sentence, for example:

"Despite this I decided to take the risk and bought it hoping I would get the planning permission for domestic use later." 'Fortunately, Sue did get permission and it took her a further year to convert the property into one house and a flat.' (The Real Homes Magazine, April 2001:41) The problem here is implied in that she might not be given a permission to transfer a place from a business property to a domestic one. The solution which immediately follows as a comment by the narrator is marked by the adverb "fortunately."

\subsubsection{The Final result (evaluation)}

This phase is equivalent to the evaluation section in the basic narrative structure. Throughout the narration process, the narrator often suspends his narration in order to provide an evaluation on a previous description that he believes needs evaluation. Evaluation of a narrative is further dramatized by telling "what people did rather than what they said." (Labov 1972: 373) The final result block exhibits the narrator's feelings about the rooms described and renovations that took place. Such evaluation usually occupies the last paragraph and is essential to terminate the narrative. "Lesley's love of décor, furniture and architecture has served her well. The house looks perfect and if Richard Norman Shaw could see it now he would surely be pleased to see his work so well preserved." (The Real Homes Magazine, April 2002:14) This stage witnesses the aggregation of the achievement of the major goal, the positive result stage in the problem-solution pattern and the narrator's evaluation.

"But they're thrilled with the end result. 'Considering what it looked like when we first moved in, it's a miracle that it looks the way it does now.' Says Rachel. 'We've got exactly what we wanted in terms of light and space, even though it was a hard fought battle." (House Beautiful, May 2002:28)

"Like Debbie's designs, her home combines comfy, old-fashioned quality with a contemporary look." (House Beautiful, June 2002:38)

"Sue's dedication to the cause has paid off as she has created a unique and relaxing living space." (The Real Homes Magazine, April 2002:44)

"The couple are delighted with their new home." (Ideal Home, June 2002:60)

The narrator's evaluation in "has paid off" "Comfy, old-fashioned quality, contemporary look", the achievement of the original goal "We've got exactly what we wanted" and the positive result to the major problem "they're thrilled with the 
end result" are all combined in the last paragraph presenting the final result stage. In addition, writers enunciate their narrative clauses by certain evaluative adverbs as "sadly" "luckily" and "fortunately" that mirror their assessment.

\section{Conclusion}

This study investigated narrative discourse in decoration magazines laying special focus on the interaction and structuring of this type of discourse. It is found that the narrative in decoration discourse shares many characteristics of narrative discourse, but deviates from it in other respects. Primarily, it exhibits a high degree of interaction between the writer and the reader. This is evident in several instances of informal language usage, direct address and intimacy with the reader. Other common informalities can be witnessed in the abundance of idiomatic expressions, sense of humour and commonly shared cultural attributes. Events in the narrative of decoration discourse are found to follow two major patterns; the problem-solution and the goal-achievement patterns. These patterns intermingle with the five building blocks (abstract, orientation, planning, decorating process and final result) and provide a hierarchical organization and design to this type of discourse. Matching and sequential relation between clauses similarly add to the interactive nature and coherence of decoration discourse. Moreover, this type of discourse is found to be built on implicit interactive questions that are answered throughout the narrative. Causative clauses are constantly utilized as a linguistic means to justify the actions carried out by the owners. The paper scratched the surface of a many-layered area of inquiry. It is hoped that future research will be able to investigate the distinctive syntactic characteristics and lexical choices peculiar to this type of discourse or investigate the interrelation between text and image in decoration discourse.

\section{References}

\section{Primary Sources}

"As soon as I saw the details, I knew it was the house for me." Good Homes. Dec./Jan. 2002.

"At home with Heartbeat's Tricia Penrose." Homes and Ideas. July 1999.

"Back to the Future." House Beautiful. May 1999.

"Bank Statement." 25 Beautiful Homes. May 2002.

"Beautifully Bold." Inspirations for Your Home. July 2001.

"Big ideas in a big space." The Real Homes Magazine. April 2001.

"Country Chic." House Beautiful. May 2002.

"Cows used to live in our farmhouse." The Real Homes Magazine. April 2001.

"Dream factory." The Real Homes Magazine. April 2001.

"I've always loved classical looks." Ideal Home. June 2002.

"Living on top of the world." The Real Homes Magazine. April 2001.

"Love at first sight." House Beautiful. May 2002.

"Lucky Strike." House Beautiful. June 2002.

"Moving on up." The Real Homes Magazine. April 2001.

"Old School Design." The Real Homes Magazine. April 2001.

"Open Sesame." House Beautiful. May 2002.

"Our style has completely changed." Ideal Home. June 2002.

"Paradise found." House Beautiful. May 2002.

"Perfect teamwork." Inspirations for Your Home. July 2001.

"Rural Retreat." Inspirations for Your Home. May 1999.

"Rural Bliss." 25Beautiful Homes. May 2002.

"The necessary things in life." Country Homes and Interiors. July 2001.

"The Perfect Mix." House Beautiful. June 2002.

"This place is just as we want it now." Ideal Home. June 2002.

"Toiles and Stripes." Country Homes and Interiors. July 2001.

"Turn the Clock Back in Style." The Real Homes Magazine. April 2001.

"Seaside delight." House Beautiful. June 2002.

"Swedish Pastorale." Country Homes and Interiors. July 2001.

"We designed every last detail of our dream house." Ideal Home. June 2002.

"Welcome to the house of fun." The Real Homes Magazine. April 2001.

"We think the house likes being a family home again." Good Homes. Dec./Jan. 2002. 
Secondary Sources

Barwell, I. (2009). Understanding narratives and narrative understanding. The journal of Aesthetics and Art Criticism, $67,49-59$.

Berger, A. (1997). Narratives in popular culture, media, and everyday life. London and New Delhi: Sage Publications.

Burner, J. (2004). Life as narrative. Social Research, 71, 691-710. Retrieved from http://www.jstor.org/stable/40971721

Caldas-Coulthard, R. (1994). On reporting reporting: the representation of speech in factual and factional narratives. Advances in Written Text Analysis ( $1^{\text {st }} \mathrm{ed}$.). London and New York: Routledge.

Coste, D. (1989). Narrative communication. Minnesota: University of Minnesota Press.

Currie, G. (2006). Narrative representation of causes. The journal of Aesthetics and Art Criticism, 64, $309-316$.

Hoey, M. (1991). Patterns of lexis in text. Oxford: Oxford University Press.

Hoey, M. (2001). Textual interaction: an introduction to written discourse analysis. London and New York: Routledge.

Hurdley, R. (2006). Dismantling mantelpieces: narrating identities and materializing culture in the home. Sociology, 40 (4), 717-733. Retrieved from http://www.jstor.org/stable/42856891

Labov, W. (1972). Language in the inner City: Studies in the black English vernacular. Philadelphia: University of Pennsylvania Press.

Labov, W. \& Joshua W. (1967). Narrative analysis: Oral versions of personal experience." In J. Helm (Ed.), Essays on the verbal and visual arts. Seattle and London: University of Washington Press.

Lieblich, A., Tuval-Mashiach, R. \& Zilber,T. (1998). Narrative research: Reading, analysis and interpretation. London and New Delhi: Sage Publications.

Nanay, B. (2009). Narrative pictures. The journal of Aesthetics and Art Criticism, 67, 119 - 129.

Riessman, k. (1993). Narrative Analysis. London and New Delhi: Sage Publications.

Scholes, R. 1981. Language, narrative, and anti-narrative. In W. Mitchell (Ed.), On narrative (pp. 200-208). Chicago: University of Chicago Press.

Souto-Manning, M. (2014). Critical narrative analysis: the interplay of critical discourse and narrative analyses. International Journal of Qualitative Studies in Education, 27 (2), 159 - 180. doi: 10.1080/09518398.2012.737046 